\title{
ADOÇÃO DE CRIANÇAS POR CASAIS HOMOAFETIVOS: UMA REVISÃO DA LITERATURA
}

\section{ADOPTION OF CHILDREN BY HOUSING COUPLES: A LITERATURE REVIEW}

\section{Silmaria Bezerra Porcino}

Mestre em Ciências da Educação Pelo Instituto Superior de Educação Professora Lúcia Dantas-ISEL e Graduada em Serviço Social Pela Universidade Federal da Paraíba-UFPB,

Brasil. E-mail:siwmarya@hotmail.com

\section{José Marciel Araújo Porcino}

Bacharelado em Psicologia Pelas Faculdades Integradas de Patos-FIP, e acadêmico do $5^{\circ}$ Período do curso de Pedagogia da Universidade Federal da Paraíba-UFPB na modalidade de Educação a Distância-EAD, Brasil. E-mail:leicram_ap@hotmail.com.

\section{Marily Miguel Porcino}

\begin{abstract}
Bacharel em Direito Pelas Faculdades Integradas de Patos-FIP, especialista em Direito Civil
\end{abstract} e Processual Civil e Gestão Pública.

\section{Resumo:}

O presente trabalho tem por objetivo refletir sobre a adoção de crianças por casais homoafetivos, tema de significativa relevância social, considerando o grande número de crianças que aguardam para serem adotadas. Diante de um delineamento qualitativo, utiliza-se do conceito de adoção no decorrer da história e das mudanças ocorridas na interpretação do conceito de união estável atribuído pelo Supremo Tribunal Federal, possibilitando que independentemente da orientação sexual dos parceiros, estes tenham o direito de pleitear a adoção. Com isso, pode-se dizer que a proposta deste não é a de levantar uma bandeira contra ou a favor da adoção homoafetiva, mas mostrar que os homossexuais assim como, qualquer outro cidadão têm seus direitos, sendo a adoção, um deles agora devidamente assegurado. Considera-se que este estudo poderá contribuir de forma significativa para a inserção de uma nova visão na sociedade em busca da melhoria de vida daqueles que aguardam para realização do desejo de ampliar sua família

Palavras-chave: adoção, Homoafetividade, Preconceito.

\section{Abstract:}

This study aims to reflect on the adoption of children by homosexual couples, a topic of significant social relevance, considering the large number of children waiting to be adopted. In view of a qualitative delineation, the concept of adoption throughout history and changes in the interpretation of the concept of stable union attributed by the Federal Supreme Court is used, making it possible, regardless of the sexual orientation of the partners, to have the right to plead adoption. With this, it can be said that this proposal is not to raise a banner against or in favor of homoaffective adoption, but to show that homosexuals as well as any other citizen have their rights, and adoption, one of them now properly ensured. It is considered that this study can contribute significantly to the insertion of a new vision in society in search of the improvement of 
life of those who wait for the realization of the desire to expand their family.

Keywords: adoption, Homoafetividade, Preconception.

\section{Introdução}

$\mathrm{Na}$ contemporaneidade, em nossa sociedade a família é sempre vista como base para formação da pessoa, sendo a mesma responsável por proporcionar o bemestar necessário para um bom desenvolvimento psicossocial entre os mesmos. Dessa forma, baseado no princípio da liberdade e igualdade, os casais homoafetivos tem os mesmos direitos dos casais heterossexuais de constituírem suas próprias famílias, pois a base de formação desta, ou seja, o amor, carinho e respeito, certamente não irão lhes faltar.

Atualmente, nesse contexto, a adoção de crianças por casais homoafetivos é uma realidade social, logo, fazer de conta que ela não existe, não resolverá o problema daqueles que lutam pelos direitos de tornarem-se iguais em sociedade. Sociedade esta, que muitas vezes priva crianças de terem um lar por preconceito à orientação sexual (homoafetiva) do adotante. Para tanto, diante da magnitude do assunto, faz-se necessário que a população tenha acesso a essas informações pertinente, considerando a existência de inúmeras crianças a serem adotadas no Brasil.

Nesse sentido, vale ressaltar que a discussão ora em análise faz-se necessário, uma vez que é de grande relevância social, considerando o grande número de crianças que aguardam a espera de um lar. Desse modo, é preciso uma maior valorização desse ato nobre que é adotar, para que desta forma, haja maiores reflexões significativa nesse cenário. Assim, configura-se como objeto de estudo do presente artigo refletir sobre a adoção de crianças por casais homoafetivos.

\section{Breve histórico da homossexualidade}

As práticas sexuais por pessoas do mesmo sexo advêm desde tempos mais remotos e atualmente tem se amplificado, considerando que a revelação explícita do preconceito tem minimizado. Recorrendo a história esta seria uma maneira comum de relacionar-se nas civilizações Gregas e Romanas, uma vez que estas não eram tidas com anormal (FIGUEIRÊDO, 2008).

Ainda de acordo com Figueirêdo (2008, p.20) observa-se que "na antiguidade grega a pederastia, ou seja, a relação sexual entre o homem mais velho, o erastes, e o rapaz mais novo o eromenos, era aprovada e tomada como modelo de ética amorosa". Percebe-se que a pederastia, era bem vista pelos gregos, já a relação sexual entre homens com a mesma idade ou mais velho, era proibida. 
Nota-se que nessa fase o jovem se tornava eromenos entre 13 e 14 anos de idade, e geralmente ficavam na condição de passivo até os 18 anos, após atingir sua maior idade se esperava dele que o tornasse ativo, nesse momento ele estaria pronto para escolher seu futuro eromenos, iniciar esse jovem na vida sexual e escolher sua esposa (FIGUEIRÊDO, 2008).

Partindo dessa premissa, Catonné e Spencer (1994 apud FARIAS; MAIA, 2009) enfatizam que nas antigas civilizações as relações sexuais entre pessoas do mesmo sexo eram vistas como um simples ato sexual e puramente de cunho social, não se preocupando com a moral e sim com a posição que eles exerceriam nessa relação.

No Egito Antigo a relação sexual entre dois homens era mal vista socialmente e condenável. Para tanto se compreende que nas civilizações antigas não há relatos deste ato entre duas mulheres, não que a homossexualidade feminina não existisse (FARIAS; MAIA, 2009).

Desse modo, Chauí (1984 apud FARIAS; MAIA, 2009) chama atenção para descrição da visão que a homossexualidade tinha na Grécia e Roma antiga. De modo, que essa conduta era aceitável e até incentivado em determinadas situações sendo considerado como amor verdadeiro cabível de intensos sentimentos, não sendo estes rotulados e nem discriminados.

Partindo dessa concepção, Girardi (2005, p.66,67) descreve aspectos pertinentes acerca do pensamento que originou nas primeiras discussões sobre homossexualidade, tem-se:

[...] o primeiro dado importante sobre a discussão da homossexualidade se deu em 1869, quando um médico húngaro Karoly Benkert se manifestou em defesa dos homossexuais que estavam sendo perseguidos por questões políticas na Alemanha do Norte. Na carta Benkert defendia a ideia como algo inato a pessoa, não podendo ser adquirido e assim desvinculado das questões de preferência pessoal, portanto, não merecedor de juízes condenatórios por ser classificada como contrário a ordem moral e religiosa.

Nesse contexto, a homossexualidade passa a ser vista não mais como crime, mas como uma doença, e sendo doença, merecedora de tratamento, o fato de ser considerada uma doença, fez com que muitas pessoas não fossem mortas em virtudes de sua orientação sexual (GIRARDI 2005).

Mello (2012, p.202) comenta que "a homossexualidade era antes vista como uma mistura de males físicos e sociais". Nesse sentido, observa-se que essa mistura de pecado-doença-crime, ou seja, esse estigma é fruto de uma visão estereotipada que decorre de tempos passados da humanidade, e perduram até os dias atuais. Dessa forma, sabe-se que a homossexualidade não é um fato novo em nossa sociedade, ela sempre existiu e certamente não deixará de existir, cabe a própria sociedade aceitá-la ou não. 
Etimologicamente o termo de homossexualidade, é formado pela junção de dois vocábulos, um grego e outro latino: 'homo' e 'sexu'. Homo, do grego 'hómos', que significa semelhante, igual e 'sexu', do latim que está ligado ao sexo, para tanto este ato ocorre entre um casal do mesmo sexo (DOVER, 1994 apud PINTO 2012, p.5). Desse modo, Dover (1994 apud PINTO, 2012, p.5) conceitua a homossexualidade como a disposição para buscar prazer sensorial através do contato corporal com pessoas do mesmo sexo. Assim, preferindo-o ao contato com a pessoa do mesmo sexo, ao manifestar o desejo por pessoas do sexo oposto.

Desta forma, a homossexualidade, caracteriza-se pela atração sexual e afetiva entre duas pessoas do mesmo sexo, sendo aceito em algumas, em outras repreendidas, porém sabe-se que é um fato presente na humanidade desde os primórdios de sua existência (GIRARDI, 2005). Antes o exposto, conclui-se que a relação sexual entre pessoas do mesmo sexo sempre existiu na história da humanidade, seja como perversão, doença, ou qualquer outro nome que venha a caracterizar a orientação sexual da classe homoafetiva. Tanto existiu que a própria Bíblia traz de forma explicita em alguns textos, a diferença é que antes as civilizações praticavam 0 ato sem ter nomenclatura específica, nomenclatura essa que só veio a surgir no século XIX (ZAMBRANO, 2012).

\subsection{O modelo de família homoafetiva}

Para Scalquette (2009, p.15), “conceituar família não é tarefa das mais fáceis, mas uma coincidência sempre houve: família é elo formado entre pessoas decorrente do casamento". No entanto, a constituição Federal de 1988, em seu art. 266, $§ \S 3 .{ }^{\circ}$ e

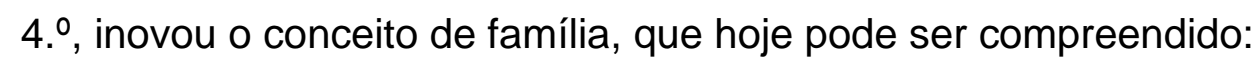

- $\quad$ Conjunto de pessoas unidas pelo casamento (cônjuges e filhos);

- $\quad$ Conjunto de pessoas unidas pela união estável-entidade familiar;

- $\quad$ Conjunto de pessoas formado por um só dos pais com sua prole- família monoparental.

De acordo com o artigo acima mencionado, a família originada da relação homoafetiva não é considerada um modelo de entidade familiar, uma vez que ainda não houve reconhecimento por parte dos legisladores brasileiros, ou seja, não houve alteração da legislação em vigor que trata do direito de família CF/88 e Código Civil Brasileiro/2002, apesar da manifestação do Supremo Tribunal Federal, que em decisão de um caso isolado/concreto, reconheceu a equiparação da relação homoafetiva, nos seus direitos e deveres, com a união estável, entidade familiar devidamente regulamentada (SCALQUETTE, 2009). 
Atualmente, de acordo com 0 art. 266, $\S 3^{\circ}$, $\S 4^{\circ}$ da Constituição Federal de 1988, temos uma diversidade de modelos de famílias; dentre elas a matrimonial, a mais antiga de todas oriunda do casamento (civil) entre o homem e a mulher, onde direitos e deveres são iguais. Tem-se também a não matrimonial, fruto da união estável e da entidade monoparental, ambas devidamente regulamentadas, a primeira constituída da união entre o homem e a mulher, tendo seus direitos e deveres compatíveis com as dos membros da primeira instituição familiar. A segunda respectivamente, constituída por apenas um dos genitores e sua prole, onde os direitos da prole são devidamente reconhecidos (BRASIL, 1988).

As representações de modelo de família adquiriram novas referências e significados acerca de sua formação e de seus direitos, em que as relações entre casais do mesmo sexo ganharam discussões nos espaços sociais, psíquicos e jurídicos (MELO, 2012).

Segundo Peres (2006 apud FARIAS; MAIA, 2009), tendo em vista as funções de família, faz-se necessário considerar o casal homossexual como modelo de família, uma vez que estes se encontram aptos para o exercício das funções materna/paterna, mesmo que não obtida de forma natural.

Dentre a variedade de modelos de família existente, uma ganhou maior destaque a família nuclear conhecida por sua base tradicional composta por pai, mãe e filhos, modelo aceito e tido pela sociedade como normal; ocorrendo assim, transformações nesses modelos havendo substituições por outras formas de famílias as denominadas alternativas (PRADO, 1985).

Nesse sentido, denominam-se famílias alternativas as diversas experiências substitutivas de famílias, podendo constituir-se a partir de novas uniões com filhos ou sem filhos de relações anteriores, ou através da união livre que pode ser um casamento monogâmico. Outras formas são as comunidades que nascem como alternativas de minimizar os problemas familiares na contemporaneidade, como os hippies, que possuem um modelo particular de convivência e que mantêm regras monogâmicas entre os casais. Podem-se citar como modelo alternativo, famílias constituídas por gays, lésbicas, bissexuais e travestis, dentro dessa modalidade o modelo de família homoafetiva que é o objeto do presente estudo (PRADO, 1985).

\subsection{Sexualidade e o direito}

A sexualidade vem cada vez mais se tornando assunto de debate entre os estudiosos, sejam eles da psicologia, sociologia, jurídica e áreas afins. É algo inerente ao ser humano, segundo a Psicanálise de Freud a sexualidade está presente no indivíduo desde o momento que nasce, estando esta relacionada diretamente a intimidade, desejos, fantasias e satisfações humanas (FREUD, 1996). 
A questão do direito e da sexualidade é algo complexo e polêmico em nossa sociedade, especificamente quando se tem uma orientação sexual diferente da grande maioria, que se diz heterossexual, neste caso sendo os homossexuais considerados uma minoria em tese, o direito a exercer sua opção livremente torna-se mais difícil.

A Constituição Federal de 1988 retrata nos seus dispositivos a igualdade de todos e condena qualquer tipo de discriminação. $O$ artigo $3^{\circ}, \mathrm{CF} / 88$, enuncia os objetivos fundamentais da República, "construir uma sociedade livre, justa e solidária” e "promover o bem de todos, sem preconceito de origens, raça, cor, sexo, idade e quaisquer outras formas de discriminação" e ainda em seu art. $5^{\circ}$, reafirma que todos serão iguais perante a lei, sem distinção de qualquer natureza (BRASIL, 1988).

Portanto, se a própria Constituição Federal assegura o direito fundamental a todos os indivíduos, proíbe toda e qualquer forma de preconceito, não se pode entender o porquê da discriminação com aqueles que não são considerados um modelo a ser seguido, haja vista, que o devido documento legal não proíbe a relação homoafetiva, mas também, não regulamenta em seus dispositivos as mudanças públicas e notórias ocorridas no âmbito social.

Ao longo de seu percurso histórico, os homossexuais vêm conseguindo conquistas significativas, recentemente em 05/05/2011, o Supremo Tribunal Federal (STF), reconheceu por unanimidade a existência de união estável entre casais do mesmo sexo, com entidade familiar, com isso, direitos que antes eram exclusivos para casais heterossexuais, hoje podem ser usufruídos pelos casais homossexuais como: herança, pensão alimentícia, adoção em conjunto, casamento, pensão previdenciária, dentre outros.

Vale ressaltar, que a legislação brasileira (Constituição Federal, Código Civil e demais normas legislativas), ainda não reconheceu a união estável entre casais do mesmo sexo, como mostra o art. 226 (caput e $\S 3^{\circ}$ ) da CF/88 e o Código Civil Brasileiro/ 2002 no seu art. 1.723 que trata do reconhecimento da união estável entre tão somente o homem e a mulher.

Art.226. A família, base da sociedade, tem especial proteção do Estado. §3ำ para efeito da proteção do Estado, é reconhecida a união estável entre o homem e a mulher como entidade familiar, devendo a lei facilitar sua conversão em casamento (BRASIL, 2006, p.141).

Art. 1.723. É reconhecida como entidade familiar a união estável entre o homem e a mulher, configurada na convivência pública, continua e duradoura e estabelecida com o objetivo de constituição de família (BRASIL, 2003, p.761).

Contudo, vários foram os direitos já conquistados pelos homossexuais, o que antes era uma utopia para os casais homoafetivos, atualmente ganhou um leque de considerações como a diminuição do preconceito, a equiparação da união estável, direito a adoção, dentre outros, diante dessas conquistas abriu-se uma sequência para 
exercer os princípios básicos dos direitos humanos, o direito a dignidade, liberdade e igualdade.

\title{
2.3 Adoção homoafetiva
}

Adoção pode ser compreendida como um ato livre e nobre, pelo qual um indivíduo busca meios para concretização do sonho de tornarem-se pais, podendo fundamentar-se tanto na razão quanto no coração, onde o vínculo será construído diariamente independente de laços sanguíneos (LEVINZON, 2004).

O tema adoção causa discussões polêmicas principalmente quando se perpassa por casais homossexuais, em que se têm preconceitos estereotipados. Com isso, a adoção é um ato jurídico, de requisitos legais, sem laços sanguíneos ou afins, constituindo uma família, obtendo um filho que não lhe é consanguíneo (DINIZ, 2007).

A respeito da adoção a desembargadora Dias (2005, p. 426), enfatiza que:

\begin{abstract}
A adoção constitui um parentesco eletivo, pois decorre exclusivamente de um ato de vontade. Trata-se de modalidade de filiação construída no amor, na feliz expressão de Luiz Edson Fachion, que gera vínculo de parentesco por opção. A adoção consagra a paternidade sócio afetiva, baseando-se não no fator biológico, mas em fator sociológico. A verdadeira paternidade funda-se no desejo de amar e ser amado.
\end{abstract}

Nesse contexto, pode-se dizer que a adoção é o ato legal de dar e receber amor, meio pelo qual, muitas pessoas buscam para a realização do sonho da maternidade/paternidade. Contudo, após a transferência do poder legal dos pais biológicos (parentes consanguíneos) aos pais adotivos, o ato torna-se totalmente irrevogável, em outras palavras, os pais biológicos são destituídos do pátrio poder. Atualmente, não se pode tratar da adoção sem tratar as consideradas adoções especiais, que nesse caso específico, seriam as adoções por casais homoafetivos, originando um novo modelo de família totalmente diferente da tradicional nuclear, composta por pai, mãe e filhos.

Vale salientar que a legislação brasileira não faz nenhum tipo de restrição a respeito da orientação sexual da parte adotante, quanto à adoção por casal homoafetivo, conclui-se que esta só será devidamente regulamentada se houver um reconhecimento deste tipo de relacionamento como união estável, conforme art. 226 da CF/88 e Código Cível Brasileiro/2002, art. 1.723, caso contrário, poderão utilizar-se das lacunas existentes na legislação em vigor, ou seja, a adoção por apenas um dos membros do casal homoafetivo, constituindo-se uma espécie de família monoparental (abaixo analisada), na teoria, mas que na prática formará uma família propriamente dita (pai/pai/filho; mãe/mãe/filho), pois se sabe que contemporaneidade é grande o número de casais do mesmo sexo que vive em união estável e duradoura.

Para Weber $(2011$, p.50,51), “[...] a questão da adoção por casais homossexuais no Brasil ainda leva um bom período de tempo até ser discutida de 
maneira sistemática. No entanto, é uma questão que não pode mais ser ignorada como se ela não existisse".

Segundo a referida autora, no Brasil, a adoção é entendida como uma alternativa para se ter filhos os quais não foram gerados biologicamente e que seria uma forma de constituir uma família. Assim, existindo duas formas: A adoção legal, e adoção à brasileira.

É pensando na constituição familiar que muitos casais homossexuais buscam meios para concretização desse sonho, dentre estes estão á adoção por uma só pessoa, sendo esse tipo de adoção considerada legal realizada mediante serviços do juizado da infância e juventude. Configurando assim, o modelo de família monoparental.

Diante da burocracia no processo legal de adoção, uma prática tornou-se comum entre casais homoafetivos e heterossexuais, no Brasil, é a adoção à brasileira, essa práxis consiste em registrar no cartório uma criança em nome dos adotantes como se fosse seu filho biológico sem o devido processo legal; esse tipo de adoção é considerado "adoção simulada" prevista no art.242, Código Penal Brasileiro, cuja pena é de reclusão ou detenção (BRASIL,1940).

CPB,art.242-"Dar parto alheio como próprio; registrar como seu o filho de outrem; ocultar recém-nascido ou substituí-lo, suprimindo ou alterando direito inerente ao estado civil" (BRASIL,1981,p.342). Pena-reclusão, de dois a seis anos (BRASIL, 1981, p.342).

O tipo de adoção, acima citada, é considerado informal/ilegal no Brasil, uma maneira de burlar a legislação em vigor, uma vez que não passa pelos tramites legais, porém é uma das formas mais rápidas de se adotar uma criança.

A temática da adoção por casais homoafetivos é algo que envolve mitos e preconceitos, dentre estes está à questão que mais gera discussão entre os estudiosos do tema, acerca dos futuros prejuízos causados a criança por conviver em um lar, onde a orientação sexual é homossexual, como também, a convivência com duas pessoas do mesmo sexo não sabendo assim diferenciar os respectivos papéis de pai e mãe. A diferenciação das figuras de pai/ homem e mãe/ mulher no desenvolvimento da criança adotada por casais homossexual vêm dividir opiniões no quesito que pode implicar na representação de causas ou prejuízos, por faltar um dos seus elementos significativos na representação simbólica entre as figuras de pai e mãe.

Nesse sentido, alguns estudiosos descrevem que é essencial a presença das figuras do pai e da mãe para o desenvolvimento da criança. $E$ que no caso de casais homoafetivos uma dessas figuras estaria faltando simbolicamente (FARIAS; MAIA, 2009). 
Dentro dessa perspectiva, Leite (2002 in FARIAS; MAIA, p.110) sobre a falta significante da figura que represente o pai e mãe.

[...] isso provocaria na criança falta de capacidade de reconhecer as diferenças entre os sexos, além do que não iriam presenciar em seus pais/mães, aspectos eróticos e amorosos em relação ao sexo oposto, além disso, ainda teria muita dificuldade de ser inserida no meio social.

Vale ressaltar, que o referido autor se coloca de maneira contrária a maioria dos autores pesquisadores, contrariando assim, estudos e pesquisas existentes sobre 0 assunto em questão, as pesquisas mostram não haver diferença no desenvolvimento da criança sejam elas adotadas por casais homossexuais ou heterossexuais. A criança não terá problemas em sua inserção no meio social por conta da orientação sexual de seus pais, ela terá problemas e traumas se não tiver um ambiente afetuoso, carinhoso, o que comer, onde morar, não estudar, isso sim deixa qualquer ser humano traumatizado.

Suannes (2000 in GIRARDI, 2005, p.86), mostra que: "[...] a heterossexualidade dos pais não é garantia de quase nada, ou seja, não é a orientação sexual dos pais que vai garantir a integridade das crianças, mas a personalidade deles e a forma como lidar com as necessidades infantis e seu sensível modo de construção". Nesse sentido, a adoção não poderá ser baseada na orientação sexual do adotante, pois a mesma não será fator determinante no processo, essas crianças no tocante de sua realidade precisam de uma família a qual possa lhe dar toda uma estrutura necessária como amor, carinho, cuidados, respeito e caráter para que dessa forma sejam seres humanos dignos no futuro.

Assim, a figura de pai e mãe tida pela criança como meio de proteção, não depende da condição sexual de ser heterossexual. O que se espera é que se trate de pessoas que venham assegurar para a criança, meios dignos para uma vida melhor, diante do equilíbrio de desenvolvimento biopsicossocial.

\subsection{Adoção e preconceito}

A adoção tem sido muito utilizada por pessoas que não conseguem conceber filhos biológicos. Essa prática é utilizada desde a mais remota antiguidade, podendo ser definida como a criação de um relacionamento afiliativo que envolve aspectos sociais, jurídicos e afetivos que a diferenciam da filiação biológica (REPPOLD; HUTZ, 2012).

Segundo Weber (2011, p.19) o preconceito " é uma opinião formada sem reflexão, sem sabe", que se desenvolve de influências e experiências passadas generalizadas quanto aos indivíduos. Assim, dessa forma, a sociedade preestabeleceu preconceitos sobre os sujeitos, de modo a estigmatizar, os diferentes, os excluídos, e os que não se encontram dentro dos padrões estabelecidos socialmente. 
Ainda conforme a autora supracitada, uma forma de preconceito visível na adoção seria esconder do filho adotivo sua origem, onde muitas vezes os pais na tentativa de proteger a criança e a si próprios, escondem da sociedade que possui um filho adotivo e, sem perceber estão agindo de forma equivocada. Outra forma é que "uma criança adotada sempre vai sofrer preconceitos e ser tratado diferente pelos outros" como se os filhos biológicos fossem tratados todos iguais (WEBER, 2011, p.22).

O preconceito torna-se mais visível quando se refere à adoção de crianças por casais homoafetivos, pois socialmente falando, ainda se tem em mente a velha crença de que crianças criadas por pessoas do mesmo sexo terão problemas ao serem inseridas ao meio social. Assim, nessa perspectiva, Dias (2012, p.1) destaca que "nada justifica essa estigmatizada visão que a criança sofrerá preconceito em sua inserção ao meio social, será rejeitada ou terá prejuízos futuros por viver em um lar onde a orientação é homossexual".

Contudo, mesmo diante do preconceito existente em torno da adoção de crianças por casais homoafetivos, essa temática está aos poucos sendo aceita no âmbito social. Uma vez que os casais estão cada vez mais assumindo sua orientação sexual frente à sociedade e buscando seus direitos, sendo a adoção um deles.

Todavia, várias são as posturas observadas frente à sociedade no tocante da adoção por casais homoafetivos, a respeito dos posicionamentos preconceituosos contrários a adoção pelos referidos casais. Deste modo, Figueirêdo (2008, p.108) enfatiza que "estas pessoas sustentam a ideia de que o adotado virá a ser homossexual devido à opção sexual dos pais". Ainda percorrendo esse caminho, o autor supracitado anteriormente, aponta que é impossível determinar se a criança será ou não homossexual, pois o determinismo é improvável, caso fosse esta afirmativa verdadeira, teríamos como explicar como pessoas criadas e educadas por casais heterossexuais se tornaram mais tarde homossexual.

\section{METODOLOGIA}

No tange a metodologia do presente estudo, trata-se de uma pesquisa de cunho bibliográfica ancorada em procedimento metodológico de natureza significativa em produção do conhecimento científico capaz de gerar, temas pouco explorados, intermédios dialéticos que servirão de ponto de referência para subsidiar pesquisas futuras. (LIMA \& MIOTO, 2007), Assim, impelindo na construção de novos saberes frente a determinado assunto.

Assim, dessa forma, o presente artigo, após feita a delimitação do objeto de estudo, iniciou-se levantamento bibliográfico com intuito de investigar alguns trabalhos existentes sobre o tema proposto, discutidos por autores, tais como: Weber (2011); 
Figueirêdo (2008); Farias e Maia (2009); Girardi (2005); Levinzon (2004) e Scalquette (2009). Igualmente, utilizando também, artigos científicos, teses e dissertações encontradas na base de dados eletrônicos: Scientific Electronic Library Online (Scielo), para um maior entendimento do objeto de estudo.

A referida coleta de dados, circunscreveu-se de setembro a dezembro de 2018. Ainda, nesse sentido, para coleta de dados, foram utilizados como palavras chave: adoção, homoafetividade e família homoafetiva. A análise dos dados deu-se através da técnica da leitura reflexiva ou crítica do material coletado.

Conforme, Lima e Mioto (2007), a leitura reflexiva ou crítica se dá através do estudo crítico do material orientado por critérios determinados a partir do ponto de vista do autor da obra, e busca responder de forma fidedigna aos objetivos da pesquisa. Igualmente, a síntese integrada de leitura interpretativa, implicando na interpretação do autor, acompanhada de uma inter-relação destas com o propósito do pesquisador, objetivando relacionar as ideias da obra com o problema em busca da resposta.

\section{Resultados e discussão}

Ao longo da discussão bibliográfica sobre a temática da adoção de crianças por casais homoafetivos, percebe-se que a adoção por estes casais, hoje já é um fato mais que comprovado socialmente, é uma realidade, independente do preconceito social existente. Para tanto, observou-se que a questão que envolve o tema em discussão, se reveste mais dos conceitos culturais que a sociedade tem sobre a família e sua estrutura de formação baseada na familiar nuclear composta por pai/mãe e filhos.

De tal modo, considera-se que o tema abordado é ainda algo pouco discutido em nossa sociedade. Pois, mesmo com as mudanças ocorrida no decorrer dos tempos, muitas pessoas ainda não se encontram preparadas para aceitar de forma natural a adoção por casais homoafetivos, nem tão pouco para se posicionarem a esse respeito.

Contudo, negar aos homossexuais seus direitos de se tornarem pais/mães e de constituírem suas famílias ao lado de outra pessoa do mesmo sexo, simplesmente baseado na sua orientação sexual, é negar sua própria existência. Uma vez que estes têm seus direitos garantidos em lei conforme a decisão do Supremo Tribunal Federal.

Em linhas gerais os livros e artigos científicos analisados, em sua grande maioria, trazem dados favoráveis sobre a adoção de crianças por casais homoafetivos. As pesquisas desenvolvidas na área mostram não haver nenhum tipo de prejuízo futuro para a criança em seu desenvolvimento, seja ela adotada por casais 
heterossexuais ou homossexuais. O importante é que essa criança seja acolhida e viva em um lar onde possa dar e receber amor.

Conclui-se assim, que o tipo de adoção analisada, além de não trazer prejuízos para a criança, ainda faz com que estas alcançam os mesmo benefícios das crianças adotadas por famílias cuja formação seja heterossexual. Assim, nesse sentido, compreende-se que através das obras e artigos científicos analisados no decorrer da elaboração deste artigo, pode-se constatar que os autores em sua grande maioria se posicionam de maneira favorável a adoção de crianças por casais homoafetivos, apesar de haver também posicionamentos não favoráveis em relação a esta prática.

Ao refletir sobre os posicionamentos contrários e a favor do referido tipo de adoção é de suma importância que se pense nos dois lados da questão. Ou seja, o lado do adotante e do adotado, pois é necessário pensar, que estas crianças que estão disponíveis para adoção ao serem adotadas estarão tendo a oportunidade de terem um lar, construindo assim, sua subjetividade e cidadania. Quanto ao adotante, independente de sua orientação sexual, estará dando a essa criança direitos que Ihes foi negado anteriormente, no caso específico o de ter uma família.

Sabe-se que um dos maiores impedimentos no tocante da adoção por casais homossexuais é a questão do preconceito social. Uma vez que algumas pessoas vêm mostrar suas opiniões através de manifestações contraditórias, baseadas em sua grande maioria em visões estereotipadas, totalmente equivocadas.

\section{Considerações finais}

Procurou-se no presente artigo propor uma reflexão sobre a adoção de crianças por casais homoafetivos, bem como suas principais dificuldades na efetivação do processo. Todavia, a união homoafetiva hoje se configura em união estável, ou seja, entidade familiar, passando este casal a ter os mesmos direitos e deveres do casal heterossexual sendo a adoção um deles.

Dessa forma, torna-se inaceitável que ainda se ignore esse modelo de família, uma vez que estes poderão proporcionar a estas crianças a possibilidade de ter um lar, uma família, um sobrenome e a cima de tudo pessoas que venham a amá-las. Contudo, faz-se necessário antes de qualquer tipo de julgamento, pensar no bemestar dessas crianças, analisando o que seria realmente melhor para elas, se morar nas ruas, orfanatos ou ser adotadas por um casal onde a orientação sexual é homossexual.

Para tanto, pode se dizer que a maternidade e paternidade independe da orientação sexual do adotante, podendo estas funções tanto serem exercidas pelo homem quanto pela mulher, independente da sua orientação sexual. Todavia, o que dever ser avaliado pelos setores competentes para análise do processo adotivo é tão 
somente a capacidade do suposto adotante de promover o bem do adotado, proporcionando-lhe amor, afeto, e a estrutura necessária para o seu pleno desenvolvimento, independentemente da orientação sexual do adotante.

E por fim, evidenciou-se com o presente estudo, que o preconceito em torno da adoção homoafetiva se torna pequeno diante do desejo destes casais de se tornarem pais/mães, e negar-lhes esse direito, chega a ser mais que preconceito, é desumano. Assim, espera-se que a partir dessa pesquisa, outros pesquisadores possam desenvolver pesquisa nesse campo, de modo a contribuir para adoção.

\section{Referências}

BRASIL. Código Civil anotado e legislação extravagante: atualizada até 2 de maio de 2003/ Nelson Nery Júnior, Rosa Maria de Alexandre Nery.-2.ed. Ver. Eampl.- São Paulo: Editora Revista dos Tribunais, 2003.

BRASIL. Constituição da República Federativa do Brasil: texto constitucional promulgado em 5 de outubro de 1988, com as alterações adotadas pelas Emendas Constitucionais nำ1/92 a 52/2006 e pelas Emendas Constitucionais de Revisão nำ 1 a 6/94.-Brasília: Senado Federal Subsecretaria de Edição Técnicas, 1988.

BRASIL. Código penal brasileiro: lei no 2.848. São Paulo: Manolo, 1940.

DIAS, Maria Berenice. Manual de direito das famílias. 2.ed. Porto Alegre:livraria do advogado, 2005.

Adoção homoafetiva, 2004. Disponível em:

<http://www.mariaberenice.com.br/uploads/6 - ado\%E7\%E3o homoafetiva.pdf>. Acesso em 02/10/2018.

DINIZ, Maria Helena. Curso de Direito Civil Brasileiro. V.5.22. São Paulo: saraiva 2007.

FARIAS, Maria de Oliveira; MAIA, Ana Cláudia Bortolozzi. Adoção por homossexuais: a família homoparental sob o olhar da psicologia jurídica./ Mariana de Oliveira Farias, Ana Cláudia Bortolozzi Maia./ Curitiba: Juruá, 2009.

FIGUEIRÊDO, Luiz Carlos Barros. Adoção para homossexuais. / Luiz Carlos de Barros Figueirêdo./ 1.ed. Curitiba: Juruá, 2008.

FREUD, Sigmund. Três Ensaios sobre a Sexualidade. In: Edição standard brasileira das obras psicológicas completas. Trad. Jayme Salomão. Rio de Janeiro: Imago, 1996.

GIRARDI, Viviane. Famílias contemporâneas, filiação e afeto: A possibilidade jurídica da adoção por homossexuais. Porto Alegre: livraria do advogado, 2005.

LEVINZON, Gina Khafif. Adoção. São Paulo: Casa do Psicólogo, 2004.

LIMA, Telma Cristina Sasso; MIOTO, Regina Célia Tamaso. Procedimentos metodológicos na construção do conhcimento científico: a pesquisa bibliográfica. Florianópolis- Santa Catarina, 2007. 
MELLO, Luiz. Outras famílias: A construção social da conjugalidade homossexual no Brasil. <http://www.scielo.br/pdf/cpa/n24a10.pdf>. Acesso em $05 / 10 / 2018$

PINTO, Flavia Ferreira. Adoção por homossexuais. Jus Navigandi, Teresina, ano 6, n.54, fev. 2002. Disponível em: < http://www.scielo.org.ar/scielo. php?pid=S0328$12052009000100006 \&$ script=sci_arttext\&tlng=pt >. Acessso em 15/10/2018.

PRADO, Danda. O que é família / Danda Prado. - São Paulo: Abril Cultural: Brasiliense, 1985.

REPPOLD, Caroline Tozzi; HUTZ, Claudio Simon. Reflexão social, controle percebido e motivações à adoção: Características psicossociais das mães adotivas. Porto Alegre, 2003. Disponível em:

<http://www.scielo.br/pdf/epsic/v8n1/17232.pdf> Acessso em 20/10/2018.

SCALQUETTE, Ana Cláudia Silva. Famílias \& Sucessões / Ana Cláudia S.

Scalquette. São Paulo. SP: Barros, Fischer \& Associados, 2009.

ZAMBRAVO, Elizabeth. Parentalidades “Impensáveis”: Pais/Mães, Homossexuais, Travestis e Transexuais. Horizontes Antropológicos, Porto Alegre, ano 12, n.26,p.123-143, jul/ dez. 2006. Disponível em: < http://www.scielo.br/scielo.php?pid=S010471832006000200006\&script=sci arttext>. Acesso em 23/10/2018. 